\title{
Role of Blackboard Platform in Undergraduate Education A case study on physiology learning in nurse major
}

\author{
Liu Jianxiang ${ }^{\mathrm{a}}$, Ding Yuemin ${ }^{\mathrm{a}}$, Ding Xingeng ${ }^{\mathrm{b}}$ \\ ${ }^{a}$ School of Medicine and Life Sciences, Zhejiang University City College, Hangzhou, China \\ ${ }^{b}$ Department of Materials Science and Engineering, Zhejiang University, Hangzhou, China
}

\begin{abstract}
Blackboard platform is currently used for undergraduate education in our college. To investigate its role in physiology learning, we conducted a survey on undergraduate students in nurse major. The results suggested that Blackboard platform is helpful and playing an important role in physiology learning. But compared with other learning manners, e-learning on Blackboard is neither the mostly adopted method of learning, nor the preferred means in reviewing. We conclude that Blackboard is not a substitute of textbook, but Blackboard learning may become an important complement to traditional education in undergraduate students.
\end{abstract}

Index Terms: Blackboard platform; e-learning; undergraduate

(C) 2012 Published by MECS Publisher. Selection and/or peer review under responsibility of the International Conference on E-Business System and Education Technology

\section{Introduction}

Blackboard is a powerful e-learning platform, currently applied by many colleges for undergraduate education. During the past three years, we used Blackboard (BB) platform to assist our physiological education for undergraduates in nurse major. To encourage students participate in e-learning, we adopt self-test score in Blackboard platform as $20 \%$ of final score to evaluate performance for individual student in this course. To investigate the role of BB-learning in physiology education, in last semester, we conducted a survey with a questionnaire among undergraduate students in nurse major.

\section{Methods}

\section{A. Participants}

Sixty students in nurse major, at their first year in medical school, were chosen as object for survey. Before the survey, different learning access, including traditional lecture, problem-based learning (PBL), and e-learning by

\footnotetext{
* Corresponding author.

E-mail address: liujx@zucc.edu.cn, msedxg@zju.edu.cn
} 
Blackboard platform, as well as laboratory experiment, were open for at least 10 weeks to all participating students.

\section{B. Survey}

A paper-and-pencil survey was conducted on 60 undergraduate students in nurse major. Topics of questions included attitude to BB-learning, as well as comparison of different learning access and habits. To avoid discussion among students on the questions, the questionnaires were attributed to students at class and all participants were required to submit the questionnaire immediately after finish.

\section{Results}

All 60 students finished the questionnaire on time. All answer sheets were valid. Data on three major topics of questionnaire were as follows.

\section{Is Blackboard platform helpful to physiology learning?}

Among 60 participants, 58 students agree that e-learning on Blackboard platform is helpful. As shown in Fig.1, most participants accepted Blackboard platform as a helpful tool in physiology learning.

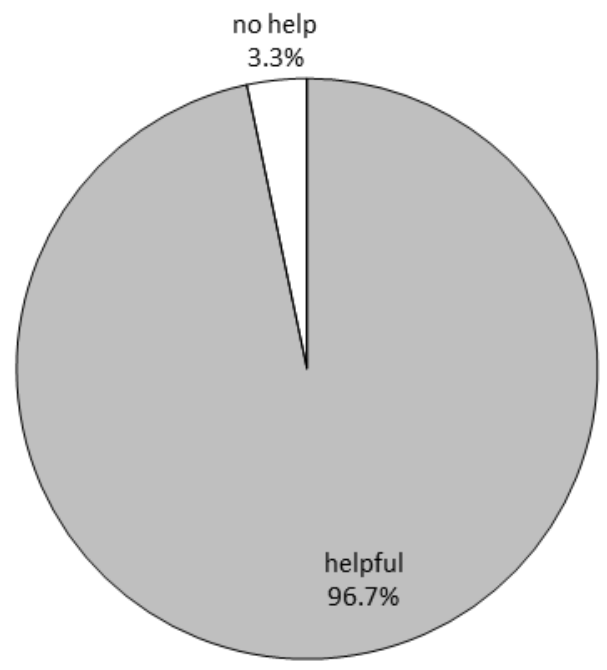

Fig.1 Students' attitude to Blackboard learning

\section{Favourite learning access in physiology}

In a multi-choices question, participants were asked to choose their favorite learning access among traditional lecture, PBL, e-learning on Blackboard platform and learning through experiment. Mostly chosen is traditional lecture (24/71), followed by PBL (23/71), experiment (17/71), e-learning on BB (7/71). The results were shown in Fig. 2. It is noticeable that among four, e-learn on BB is the least chosen access. 


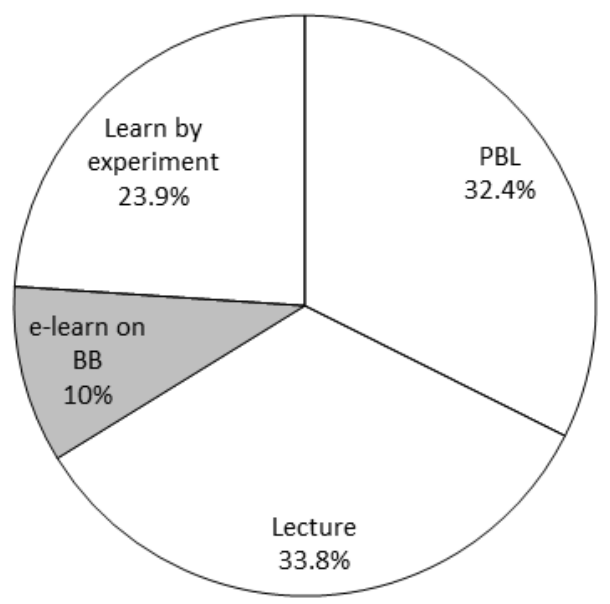

Fig.2 Favorite learning access(es)

\section{E. Favorite resources for reviewing}

In a multi-choice question, participants were asked to choose preferred review method in preparing examination. The order of preference is: textbook (43/77), BB (17/77), PPT (13/77) and others (4/77), as shown in Fig.3. Among all, 17 participants chose e-learning on BB. It is noteworthy that more than half participants chose reading textbook.

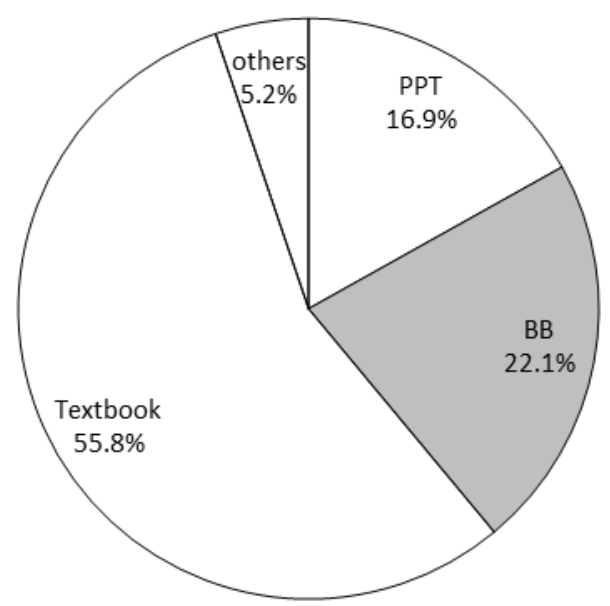

Fig.3 Favorite resource in reviewing 


\section{Discussion}

In recent years, e-learning platform based on intranet or internet technique is more and more widely applied in higher education. During past several semesters, we have used Blackboard platform as an innovation in teaching manner of physiology, to avoid some shortcomings of traditional lecture.

During the application of Blackboard system to assist education on physiology in nurse major, students were asked to participate in e-learning after class. Most of students hold a cooperative attitude in doing this. The teacher was thus encouraged to continue with the Blackboard platform construction. In this survey, we investigated the attitude of students on Blackboard platform in physiology learning.

\section{F. Blackboard learning is widely accepted by students}

As showed above, e-learning on Blackboard platform is widely accepted as a new learning route in physiology course in nurse students. As Capper listed, e-learning has following benefits: any time, any place, asynchronous interaction, group collaboration and new educational approaches [1]. Similarly, Bouhnik and Marcus summarized four advantages of e-learning: freedom to decide when each online lesson will be learned, lack of dependence on the time constraints of the lecturer, freedom to express thoughts, and ask questions, accessibility to the course's online materials at students' own election [2]. Blackboard is one of the most widely applied elearn platform in the world. Therefore, it is reasonable that most students could accept Blackboard learning.

Physiology is a subject containing many abstruse concepts and theories, some profound mechanism could not easily be deeply understood without enough time to review. Through previewing the documents about the lecture schedule and key-points of a new chapter, students could be able to be familiar with the knowledge structure of next lecture before detailed instruction. Through downloading and re-studying PPT, and finishing self-test after class as well as discussing with classmates and teachers by asking or answering questions, they could have more chance to communicate with each other. The reviewing and communication after lecture is important for either constructing knowledge or understanding details of knowledge points. Traditional education arrangement could not provide students with enough communication time or enough studying materials. Therefore, as a powerful education tool, the Blackboard system provides a platform for students to preview, to review or to discuss on key points.

\section{G. Blackboard platform is not a substitute of textbook}

Though Blackboard learning is widely accepted by students, but it does not play a key role in learning yet. In this survey, most chosen method of learning physiology is by traditional lecture. This may partly due to the intrinsic shortcomings of e-learning. As Bouhnik and Marcus analyzed, e-learning has five disadvantages: lack of a firm framework to encourage students to learn, a high level of self-discipline or self-direct required, absence of a learning atmosphere in e-learning systems, it minimizes the level of contact and the level of discussion among students, lack in interpersonal and direct interaction among students and teachers, less efficiency of the learning process compared to the face-to-face learning format [2]. These points may partly explain the result.

Another reason may be the great inertia of learning manner of those students. All surveyed students are at their first year in college. During their primary and high school education, they might have been adapted to traditional education mode: to be taught and to be tested. The person giving lecture is the one setting the papers for the examination. Therefore it could be more expectable to obtain more useful information for test from the lecture. In practice, we also noticed that, though students may visit Blackboard platform to finish self-test or to discuss upon certain questions, in most times they prefer traditional learning means to BB-learning.

It is also note-worthy that the limitation of access to internet or intranet may not be neglected. According to the regulation of the college, in campus freshmen can only visit Blackboard platform in library or computer house, but not in their dormitory. Because of the inconvenience in visiting Blackboard platform, some students may choose to read book rather than e-learn.

\section{H. Learning habit of students need to be changed}

It should be realized that, the final goal of education may not only to equip students with knowledge and techniques, but to build up the ability and habit of self-learning to meet the need in future career. Currently, the 
major, if not only, learning resource of most students is still the textbook. It indicates that, the importance of active exploration has not been well recognized [3]. The deeper reason might be the prevalence of traditional education mode, in which the students are merely passive receptors. By attending lectures, they receive and accept knowledge from professors in a passive manner. In most cases, they are not required to explore new knowledge or question what was taught.

To establish an active-learning system, we applied PBL in physiology education. As showed in Fig.2, PBL is now becoming a welcomed learning manner. Though the PBL we conducted is actually a partial PBL, it may also promote a deep approach to learning [4]. During PBL, students can bring their potential into questioning and solving questions, thereby they train and improve their abilities. Both lecture and PBL are mainly organized by the teacher and during the process students participate in a face-to-face communication with others. Compared with them, BB-learning is in lack of direct communication with teacher. Unless the student is adapted to selfexploration learning, the attraction of Blackboard platform to students may be limited.

Learning physiology through experiment is attractive, too. By operation and manipulation, students has chance to witness interesting phenomenon and testify physiological mechanisms, they may thus feel physiology interesting. Though students may watch video of physiological experiments by visiting multimedia resources in Blackboard platform, but the effect is not comparable to doing experiments by themselves.

\section{Course materials in Blackboard platform need to be qualified}

Though Blackboard platform was introduced into the college several years ago and was recently updated, in some courses, resources in Blackboard platform are still not sufficient enough to attract students. The reason may be that these teachers have not been well-trained on utilizing whole function of blackboard, in such a situation, Blackboard platform is often used as a "bulletin". Sometimes, even though a teacher may have built up a framework for a course in Blackboard platform, the course may not qualified. In some cases, teachers have no enough time to replenish or refresh course materials. To exploit more function of Blackboard platform, the teacher needs to fill course materials in Blackboard platform and update them frequently.

To meet the need of the increasing users of Blackboard learning, the college recently purchased full-function edition of Blackboard system. Thus teachers do not need to spend so much time in resources construction, and have more time to communicate with students.

\section{J. Netwok communication should be guarented}

In applying Blackboard platform into physiology education, we noticed that sometimes the condition of network limited its normal function. When students were asked to finish certain number of questions as self-test in limit time, they have to visit the Blackboard system server in same period of time. Some (about 10\% 20\%) students may meet network congestion in finishing tests or submitting their answers. If it happens frequently, students may feel frustrated or even lose their interest in BB-learning. If the hardware condition could not be improved, they may transfer the negative mood to other students.

To reduce the happening of above problem, the teacher may need to cut-down the questions number in a test, to extend the valid time of submission, and not to set time limit for finishing a test. In fact, these measures are in accordance with the main purpose of BB-learning. After all, Blackboard is merely an assistant of students in learning. Before the network condition is ensured, Blackboard may not be applied in exam.

\section{Conclusion}

In summary, Blackboard is widely accepted by nurse students in our college in physiology learning. However, Blackboard learning is neither the mostly adopted method of learning, nor the preferred means in reviewing. In conclusion, Blackboard is still not a substitute of textbook. It may partly due to the traditional learning habit of students. If functions of Blackboard platform could be exploited, it may play more important roles in undergraduate education. 


\section{References}

[1] J. Capper, "E-learning growth and promise for the developing world," TechKnowLogia, vol. 2, pp. 7-10, May/June, 2001.

[2] D. Bouhnik and T. Marcus, "Interaction in distance-learning courses," J. Am. Soc. Inform. Sci. Tech. vol. 57, pp. 299-305, February, 2006.

[3] L. Shen and G. Li, "A Design Improving Independent Learning in the Network-instruction System," J. Sichuan Normal Univ. Nat. Sci., vol. 27, pp. 328-330, May, 2004 (in Chinese).

[4] R. R. Abraham, P. Vinod, M. G. Kamath, K. Asha, and K. Ramnarayan, "Learning approaches of undergraduate medical students to physiology in a non-PBL- and partially PBL-oriented curriculum," Adv. Physiol. Educ., vol. 32, pp. 35-37, March, 2008. 